\title{
A generic model for measuring benefits of BIM as a learning tool in construction tasks
}

Weisheng $\mathrm{Lu}^{1}$, Yi Peng ${ }^{2, *}$, Qiping Shen ${ }^{3}$, and Heng $\mathrm{Li}^{4}$

\author{
${ }^{1}$ Assistant Professor, BIM Lab, Department of Real Estate and Construction, The University of Hong \\ Kong, Email Address: wilsonlu@hku.hk \\ 2,* PhD Candidate, Corresponding author, Department of Building and Real Estate, The Hong Kong \\ Polytechnic University, Address: Department of Building and Real Estate, The Hong Kong \\ Polytechnic University, Hung Hom, Kowloon, Hong Kong, P. R. China, Email Address: \\ pengyihz@gmail.com \\ ${ }^{3}$ Professor, Department of Building and Real Estate, The Hong Kong Polytechnic University, Email \\ Address: bsqpshen@polyu.edu.hk \\ ${ }^{4}$ Professor, Department of Building and Real Estate, The Hong Kong Polytechnic University, Email \\ Address: bshengli@polyu.edu.hk
}

\begin{abstract}
Over the past years, people's understanding towards Building Information Modeling (BIM) in the architecture, engineering, and construction (AEC) industry has improved significantly. BIM can be diversely recognized as a virtual design and construction environment, a communication vehicle among stakeholders, a lifelong information model, or an education platform that can be used in universities or colleges. BIM can also be used as a learning tool that can aid project teams in familiarizing themselves with a construction task, prior to commencement of the task on site. Yet, little effort has been made to measure the benefits of this kind. The aim of this research is to empirically measure the benefits of BIM as a learning tool in real-life construction tasks. The learning curves of two situations: construction tasks with and construction tasks without BIM are identified by following a series of analytical processes. The two learning curves are compared and the learning effects contributed by BIM are modeled as $L_{\text {effBIM }}$. By inputting their own data, practitioners may use this generic model to measure learning effects contributed by BIM in their own projects. The model can be used to convince potential BIM users by showing empirical evidence of BIM's benefits. It is also hoped that the model can join the concerted efforts to promote BIM's value in the AEC industry.
\end{abstract}

Keywords: Building Information Modeling (BIM), project management, learning curve, organizational learning, simulation, construction. 


\section{Introduction}

Recent years have seen a burgeoning research agenda on Building Information Modeling (BIM) in the architecture, engineering, and construction (AEC) industry. Despite a wide range of BIM definitions, certain consensus is reached that BIM is not a simple 3D model, but a process to improve the performance through the whole life cycle of buildings. Based on these understandings, BIM can be used for a wide range of purposes, e.g. design and construction integration, project management, facilities management (Azhar et al., 2008; Bazjanac, 2008; Schlueter and Thesseling 2009). BIM is argued to be a useful tool for reducing construction industry's fragmentation, improving its efficiency/effectiveness, and lowering the high costs of inadequate interoperability (Succar, 2009). BIM is also recognized as a virtual design and construction (VDC) environment, a vehicle facilitating communications amongst stakeholders, an information model that can be used throughout the project life cycle, or an education platform that can be used in universities or colleges ( $\mathrm{Lu}$ and $\mathrm{Li}$, 2011). It is changing the traditional AEC practices in a broad sense in terms of people, processes, working culture, communication, and business models. Some even advocate that the traditional AEC practices are facing a paradigm shift with the application of BIM ( $\mathrm{Lu}$ and $\mathrm{Li}, 2011)$.

Nonetheless, a widespread adoption of BIM is largely dependent on how the industry perceives its genuine benefits. Users who are to adopt BIM need to be encouraged by using empirical evidence. Investors also need to justify their investment of time and budget on BIM by discerning clear proof of its benefits. Research has shown that one of the major hurdles for adopting BIM is the justification of the additional cost and benefits ( $\mathrm{Li}$ et al., 2009). In this light, a number of studies have been conducted to identify and measure BIM’s benefits. Kaner et al. (2008) revealed clear improvement in engineering design quality, in terms of error-free drawings, and a steadily increasing improvement in labor productivity by applying BIM to four detailed case studies. Sacks et al. (2005) found that the potential benefit of adopting BIM is estimated to be in the range of 2.3 to 4.2 percent of total project cost for precast concrete companies. Sacks and Barak (2008) reported that BIM helps gain an increase of productivity ranging from $15 \%$ to $41 \%$ for cast-in-place reinforced concrete structures in the drawing phase. Patrick and Raja (2007) conducted a questionnaire survey and found that quality, on time completion and units per man-hour were ranked as the highest benefits from BIM. Comparing it 
with traditional methods, Azhar et al. (2008) stated that a case project with BIM in place has helped save an estimated $\$ 600,000$ in extras and avoid months of potential delays. Based on 32 major projects using BIM, Stanford University Center for Integrated Facilities Engineering (CIFE) (2007) logged several benefits contributed by BIM, such as up to $40 \%$ elimination of unbudgeted change, a cost estimation accuracy within $3 \%$, up to $80 \%$ reduction in time taken to generate a cost estimate, a saving of up to $10 \%$ of the contract value and up to $7 \%$ reduction in project time.

In addition to its applications in real-life projects, BIM is also recognized as a virtual environment in colleges for teaching and learning architecture, engineering, construction, and operation, etc. BIM presents an opportunity for students to acquire necessary skills by closely mimicking the real-life practices in the industry, instead of going to real sites every time. Some researchers advocated that design and construction education using BIM should be tied closely to the curriculum in schools (Ibrahim and Rahimian, 2010; Peterson et al., 2011; Sacks and Barak, 2010). The learning effects of BIM in this instance have been frequently assessed. For example, Dennis (2006) conducted a survey to investigate the learning effects relating to a curriculum for the Construction Management Department at California State University. He found that BIM appeared to have a small, but positive influence on plan reading skills. Later, Dennis (2007) conducted a similar survey and found that BIM appeared to have a positive influence on estimating. Hedges and Denzer (2008) found that BIM promotes clearly defined roles in the group-based classroom management approach of team learning, which encourages the students to pursue more rigorous investigations of design alternatives.

A closer investigation of the above references reveals that few have actually examined into BIM which can also be used as a tool for organizational learning in real-life construction projects. "Learning by doing” can be conducted in BIM as a virtual environment which is supposed to be less expensive than building a physical structure. This is particularly useful considering that physical construction is often expensive and difficult to reverse, if not completely impossible. Learning from the virtual environment in advance is expected to benefit the physical construction erection at a later stage. Li et al. (2009) reported a case of a high-rise building in Hong Kong where BIM was adopted to rehearse and optimize the construction plan for a typical floor which normally accounts for an 'N-day cycle'. BIM as a learning tool has also been applied in other construction activities such as 
training field staff, occupational heath and safety (OHS), operational of construction machinery, and logistic planning (Becerik-Gerber and Kensek, 2010; Eastman et al., 2008; Fox and Hietanen, 2007; Sacks et al., 2009; Sacks et al., 2010a; Sacks et al., 2010b). BIM has also been reported to be used in constructability analysis and process identification, which contain learning process per se (Li et al., 2008a; Li et al., 2008b). The learning effects might be phenomenal in many repetitive construction field operations ranging from smaller ones such as fixing, molding, concreting to larger ones including the construction of a standard floor. Unfortunately, these learning effects contributed by BIM have rarely been identified and measured.

The main purpose of this research is to empirically modeling the learning effects contributed by BIM in real-life construction tasks. Instead of focusing on a particular piece of construction task, this paper aims to develop a generic model $L_{\text {effBIm }}$ that allows BIM users to assess learning effects by inputting their own project data. The model can be used to convince AEC practitioners by showing empirical evidence of BIM's benefits. The model also enables BIM users to justify the investment on BIM. It is hoped that the model, by identifying and measuring BIM's benefits, can join the concerted efforts to promote BIM's value in the AEC industry. The rest of the paper comprises of four sections. From a methodological point of view, Section 2 reviews the literature on the learning curve and explores its implications for this research. Section 3 describes the methodology for measuring the learning effects contributed by BIM. With the aid of mathematical language and graphic tools, a series of six analytical processes are introduced to derive the generic model $L_{\text {effBIM }}$. Using a case study, Section 4 demonstrates how the $L_{\text {effBIM }}$ can be used in real-life construction tasks. Section 5 draws the conclusions and proposes the directions for further research.

\section{The learning curve}

Learning effects tend to follow a learning curve. The learning curve was originally developed from an empirical study in airplane firms by Wright in 1936 (Adler and Clark, 1991), and it is still popular. The basic theory behind the learning curve is that as a worker or a project team learns by doing, the more often he or the team repeats an operation, the more efficient he or the team becomes (Couto and Teixeira, 2005). This phenomenon is clear in many repetitive production activities and is known as the learning experience or learning effect. The learning curve can help identify the learning effects, or in 
other words, the relationship between performance improvement and the accumulative experience through learning. Here the performance is often measured using productivity in several terms such as man-hours/cycle, cost/cycle, and time/cycle (e.g. Thomas, 1986; Adler and Clark, 1991; Farghal et al., 1997; Couto and Teixeira, 2005).

However, the learning curve is not only a curve reflecting the net direct labor productivity due to laborer's own effort and skill (Lieberman, 1987). Learning behind the learning curve results from an integrated effort of many factors such as direct labor, indirect labor, technical personnel and managerial or engineering action to change the technology, the equipment, the processes, or the human capital (Oglesby et al., 1989; Lutz, 1994). It should be pointed out that previous studies focus on individual workers in repetitive labor tasks, and the learning effects in managerial tasks such as project plan, jobsite management, and innovation have not been fully addressed. Nevertheless, the advantage of the learning curve is that it can describe the integrated effort of all these factors. Alder and Clark (1991) called this learning curve a "catch-all” model with one explanatory variable “experience”.

The classical learning curve model is a power function, which can be further represented as straight lines in the logarithmic coordinate as shown in Fig. 1. The learning effects can be analyzed through three stages in Fig. 1. The learning curve theory states that whenever the production quantity of a new or changed product doubles, the unit or cumulative average cost (hours, man-hours, dollars, etc.) will decline by a certain percentage of the previous unit or cumulative average rate (Thomas et al., 1986). This percentage is called the learning rate and identifies the learning achieved. It also establishes the slope of the learning curve, as can be seen in Fig. 1. As a satisfactory industry-wide learning curve model for all products or activities does not exist, many other learning curve forms have been developed as shown in Table 1. 


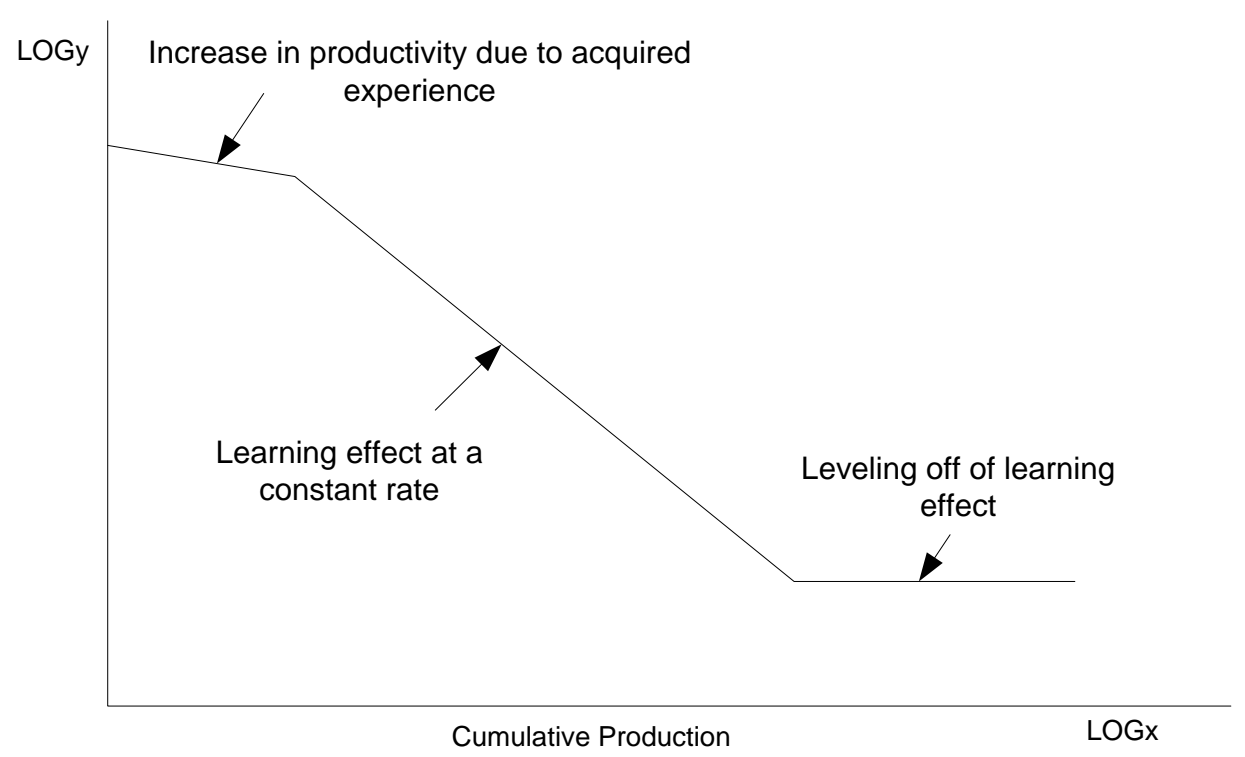

Fig. 1 Three stages in a theoretical learning curve

Table $1 \mathrm{~A}$ summary of the learning curve models

\begin{tabular}{|c|c|c|c|c|}
\hline Type & Formula & Derivative & Remarks & References \\
\hline Linear & $\log y=a+b \log x$ & $\begin{array}{l}\text { Linear } x, y ; \text { Linear } x, \log y \text {; } \\
\text { Linear logx, } y \text {; }\end{array}$ & $\begin{array}{l}\text { Simplest, } \\
\text { constant } \\
\text { learning rate }\end{array}$ & $\begin{array}{l}\text { Wright,1936; } \\
\text { Hartley,1965 } \\
\text {; }\end{array}$ \\
\hline Quadratic & $\log y=a+b(\log x)+c(\log x)^{2}$ & $\begin{array}{l}\text { Quadratic x, y; Quadratic x, logy; } \\
\text { Quadratic logx, y; }\end{array}$ & $\begin{array}{l}\text { Learning rate } \\
\text { is not a } \\
\text { constant }\end{array}$ & $\begin{array}{l}\text { Everett and } \\
\text { Farghal, } \\
1994 \text {; } \\
\text { Nembhard } \\
\text { and Uzumeri, } \\
2000\end{array}$ \\
\hline Cubic & $\begin{aligned} \log y= & a+b(\log x)+ \\
& c(\log x)^{2}+d(\log x)^{3}\end{aligned}$ & $\begin{array}{l}\text { Cubic x, y; Cubic x, logy; Cubic } \\
\log x, y \text {; }\end{array}$ & $\begin{array}{l}\text { Learning rate } \\
\text { is not a } \\
\text { constant }\end{array}$ & $\begin{array}{l}\text { Everett and } \\
\text { Farghal, } \\
\text { 1994; }\end{array}$ \\
\hline $\begin{array}{l}\text { DeJong’s } \\
\text { formula }\end{array}$ & $y=a\left[M+(1-M) x^{-b}\right]$ & & $\begin{array}{l}\text { Incorporate } \\
\text { the } \\
\text { proportion of } \\
\text { manual work } \\
\text { in a } \\
\text { man-machin } \\
\text { e work }\end{array}$ & $\begin{array}{l}\text { DeJong, } \\
\text { 1957; } \\
\text { Nembhard } \\
\text { and Uzumeri, } \\
2000\end{array}$ \\
\hline S-curve & $y=a\left[M+(1-M)(x+p)^{b}\right]$ & & $\begin{array}{l}\text { The start-up } \\
\text { of the } \\
\text { learning } \\
\text { process is } \\
\text { more gradual } \\
\text { than linear }\end{array}$ & $\begin{array}{l}\text { Carr, 1946; } \\
\text { Nembhard } \\
\text { and Uzumeri, } \\
2000\end{array}$ \\
\hline
\end{tabular}




\begin{tabular}{|c|c|c|c|c|}
\hline & & & $\begin{array}{l}\text { model } \\
\text { suggest }\end{array}$ & \\
\hline Stanford-B & $y=a(x+p)^{b}$ & & $\begin{array}{l}\text { Assume } \\
\text { acquired } \\
\text { experience } \\
\text { before } \\
\text { learning }\end{array}$ & $\begin{array}{l}\text { Asher,1956; } \\
\text { Nembhard } \\
\text { and Uzumeri, } \\
2000\end{array}$ \\
\hline $\begin{array}{l}\text { Exponentia } \\
l\end{array}$ & $y=k\left(1-e^{-x / r}\right)$ & $y=k\left(1-e^{-(x+p) / r}\right)$ & $\begin{array}{l}\text { Learning by } \\
\text { individuals } \\
\text { for both } \\
\text { manual an } \\
\text { conceptual } \\
\text { skills }\end{array}$ & $\begin{array}{l}\text { Mazur and } \\
\text { Hastie,1978; } \\
\text { Nembhard } \\
\text { and Uzumeri, } \\
2000\end{array}$ \\
\hline Hyperbolic & $y=k[x /(x+r)]$ & $y=k[(x+p) /(x+p+r)]$ & $\begin{array}{l}\text { Learning by } \\
\text { individuals } \\
\text { for both } \\
\text { manual an } \\
\text { conceptual }\end{array}$ & $\begin{array}{l}\text { Mazur and } \\
\text { Hastie,1978; } \\
\text { Nembhard } \\
\text { and Uzumeri, } \\
\text { 2000; }\end{array}$ \\
\hline & & & skills & $\begin{array}{l}\text { Wong et } \\
\text { al.,2007 }\end{array}$ \\
\hline
\end{tabular}

* The explanation of the symbol is listed in the Appendix I

The learning curve has been widely used to investigate learning in the AEC sector, due to its strengths in facilitating cost control, forecasting and strategic planning. For example, research has been conducted to find a "best-fit" mathematical learning curve model to describe the learning effects in a set of repetitive construction activities via historical data (e.g. Thomas et al., 1986; Everett and Farghal, 1994; Lutz et al., 1994; Couto and Teixeira, 2005). Studies have also been conducted to predict future performance through learning curves (Everett and Farghal, 1997; Farghal and Everett, 1997; Wong et al., 2007). One may argue that a multiple regression (MR) model or an artificial neural network (ANN) can reflect this, too. Why does it have to be the learning curve? Wong et al. (2007) and Ling and Liu (2004) suggested that the MR approach assumes linear relationship between learning and performance thus leads to unsatisfactory results. In addition, the MR approach might not be feasible, particularly when there are many casual factors while the data used for regression is insufficient (Nembhard and Uzumeri, 2000). ANN might generate satisfactory results, but due to its "black-box computation process," it is difficult to interpret the implications of the models (Dikmen et al. 2005). Therefore, the learning curve is recognized as a feasible tool to model the learning effects 
contributed by BIM in real-life construction tasks.

\section{Methodology and the learning effects model of BIM $L_{\text {effBIM }}$}

After a detailed review of literature on the learning curve, a methodology for this present research becomes clear. In order to measure the learning effects contributed by BIM, learning curves of two situations are identified: construction tasks with BIM assisting in learning and those without. If the two situations are identical except for one factor - BIM, the learning effects contributed by BIM can be modeled by comparing the two learning curves. Although the rationale underlying the methodology is straightforward, the learning effects must be identified by following a series of analytical processes (Fig. 2).

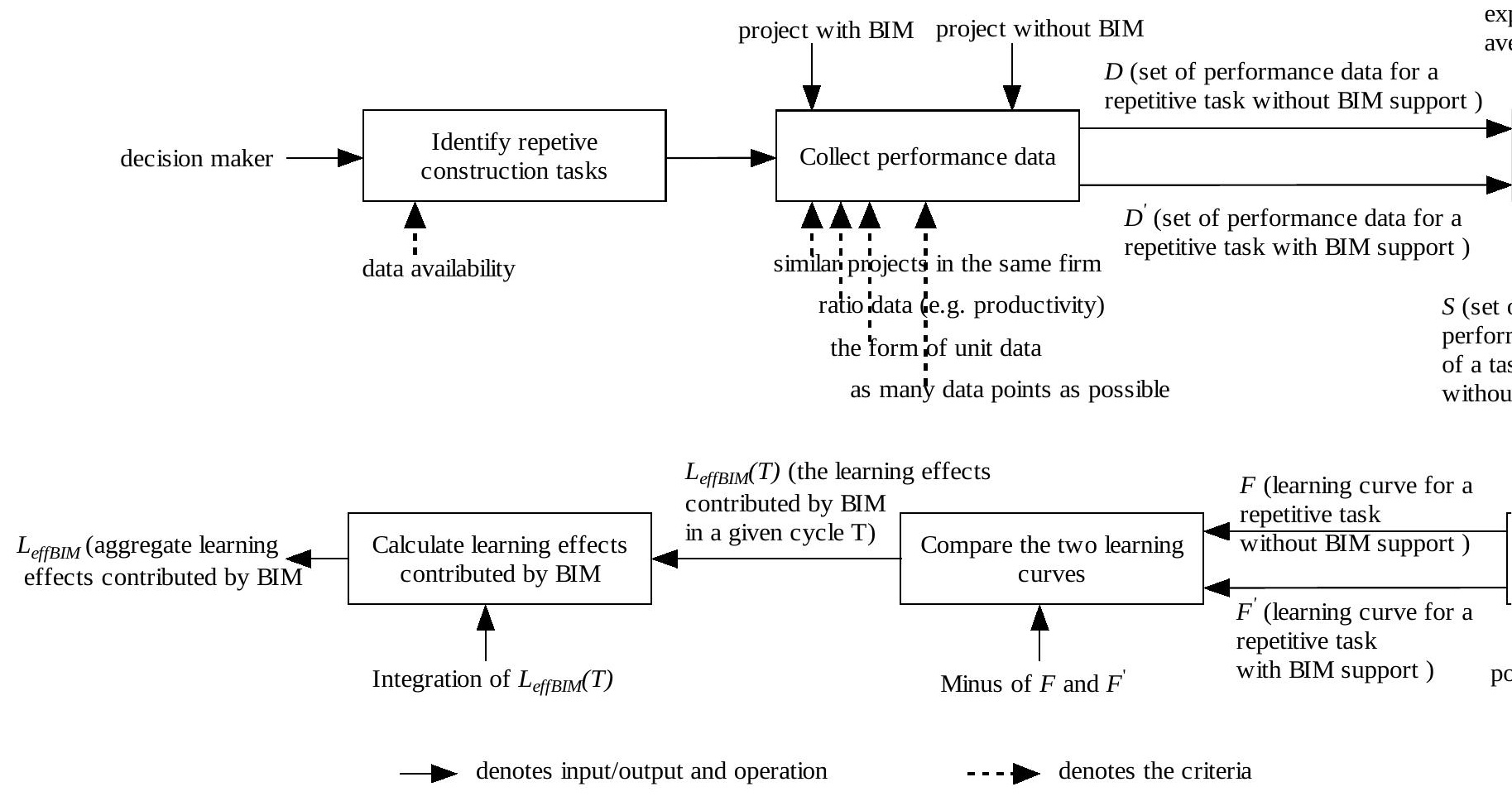

Fig. 2 Flow chart of modeling BIM's learning effects in construction tasks

\section{Step 1: Identify repetitive construction tasks to study}

In this step, the decision makers will identify the concerned repetitive construction task. As aforementioned, the learning effects reside in repetitive construction activities. However, the scale of these repetitive construction tasks varies. They can be small scale activities such as assembling and 
dismantling formwork, concreting, erection of plaster board partitions, precast plant, stonecutting, match casting, steel erection, and sewer-line installation (Everett and Farghal, 1994; Lutz et al., 1994). They can also be large scale repetitive works such as construction of multi-story residential structures, and road construction (Thomas et al., 1986; Lutz et al., 1994). Notably, Couto and Teixeira (2005) integrated the construction tasks required for the erection of a building floor level into a single repetitive construction activity and investigated its learning effects in the development of a set of seven identical housing buildings. In addition to the physical execution of a project, some project management activities such as project planning and site coordination could also be investigated with regard to the potential learning effects residing in them.

\section{Step 2: Collect performance data}

In this step, performance data of the repetitive construction tasks will be collected from projects. Ideally, two identical projects with only one factor of BIM being different should be found so as to conduct the designed comparison. Yet, in real construction practice, it is hardly possible to find two such projects. In real situation, there are many other variables such as site logistic plan, the project manager’s leadership, and workers’ craftsmanship, making any site a unique one.

In view of this, good research efforts have been made to reduce the uniqueness and make the two sets of data being of comparability, if not entirely identical. Firstly, for example, one can select similar

projects (in terms of gross floor areas, completion duration, investment) from the same company which has same organizational culture, working capability, and so on. Secondly, as introduced below, data format is pondered iteratively to reduce the impact of factors such as floor areas, number of workers, etc. Thirdly, the data sets will go through the 'data processing' described in Step 3 to reduce noise or scatter of data collected from turbulent construction sites.

Appropriate data format for measuring project performance is essential in this study. In line with previous references (e.g. Thomas et al., 1986; Alder and Clark, 1991; Farghal and Everett, 1997; Couto and Teixeira, 2005), the performance of the construction work can be measured by using varying terms such as man-hours/cycle, cost/cycle, and time/cycle. Here the cycle stands for the piece of repetitive construction task. Ratio data such as productivity in man-hour $/ \mathrm{m}^{2}$ can be adopted to 
reduce the impact of factors such as floor areas, number of workers, etc, which differentiate the two projects. Furthermore, Thomas et al. (1986) suggested that a researcher generally has the choice of using unit data or cumulative average data in applying the learning curve theory. Unit data is the time, cost, man-hours, or productivity for completing a given cycle. Cumulative average data is the average time, cost, man-hours, or productivity to complete all cycles. Everett and Farghal (1997) discussed the strengths and weaknesses of the two types of data, and found out that an exponentially weighted average processing of unit data provides a better basis for modeling the learning curve. To this end, a decision was taken in this paper to collect unit form of productivity in man-hour $/ \mathrm{m}^{2}$ and process it using the exponentially weighted average, which will be elaborated in Step 3 - data processing.

In addition, the number of data points is a critical issue for learning curve fitting. Although one can find a curve fitting into any number of data points anyway, the curve may not be able to describe a real situation. This echoes with Everett and Farghal (1994), who critiqued that previous research used only four data points, and hence most of the learning curves identified are unconvinced. It is thus suggested that as many data points as possible are to be collected in such a measurement exercise.

The data source for the performance data is also critical. The research by Thomas et al. (1986), Everett and Farghal (1994), Wong et al. (2007) accessed data from public resources such as United Nations Committee on Housing, Building, and Planning or Performance Assessment Scoring System (PASS) used by the Hong Kong Housing Department (HKHD). To model learning effects contributed by BIM, more precise and tailor-made data is needed. One can derive the data (e.g. man-hour/cycle, time/cycle, cost/cycle) from site logs, time sheets filled by employees, progress reports, inventory records, suppliers' material/labor forms, etc. The process of distilling the performance data is more convenient today as many project management tasks are facilitated by software (e.g. Microsoft Project, Primavera P6). It is even more feasible with increasing application of integrating construction process documentation into BIM (Goedert and Meadati, 2008).

As a result of the Step 2, two sets of performance data will be collected. They can be defined in mathematical language as shown in Equations (1) and (2). 


$$
\begin{array}{ll}
D=\left\{D_{1}, D_{2}, D_{3}, \ldots \ldots, D_{m}\right\} & \text { Equation (1) } \\
D^{\prime}=\left\{D_{1}^{\prime}, D_{2}^{\prime}, D_{3}^{\prime}, \ldots \ldots, D_{n}^{\prime}\right\} & \text { Equation (2) }
\end{array}
$$

Where $D$ is the set of performance data for a repetitive construction task without BIM support,

while $D^{\prime}$ denotes the set of performance data of a repetitive construction task with BIM support, and $m$ and $n$ are the cycle numbers of each task.

\section{Step 3: Data processing}

This step aims to smooth the data. Due to the complex and turbulent environment in a construction site, the data usually contains a great deal of noise or scatter. Measures should be found to smooth out the noise of the data before the best-fit learning curve is modeled. As discussed previously, Everett and Farghal (1997) suggested that the exponentially weighted average of unit data offers a better basis for modeling the learning curve. The rational behind the exponential weighted average equation is that the previous average contains information about all prior cycles should be counted more importantly than a single new observation. The exponential weighted average equation is:

$S_{i}=\alpha D_{i}+(1-\alpha) S_{i-1}$

Where $i$ is the cycle, $S_{i}$ is the smoothed performance data for cycle $i, D_{i}$ is the original performance data collected from cycle $i, S_{i-1}$ is the smoothed performance data for cycle $i-1, \alpha$ is the weighting factor or smoothing parameter decided by the modeler.

By applying the equation to the datasets of $D$ and $D$ ', two sets of smoothed performance data can be derived in this step as shown in Equations (3) and (4):

$$
S=\left\{S_{1}, S_{2}, S_{3}, \ldots \ldots, S_{m}\right\} \text { Equation (3) }
$$

$S$ is the set of smoothed performance data of a construction task without BIM support where $S_{m}=\alpha D_{m}+(1-\alpha) S_{m-1}$

and

$$
S^{\prime}=\left\{S_{1}^{\prime}, S_{2}^{\prime}, S_{3}^{\prime}, \ldots \ldots, S_{n}^{\prime}\right\} \text { Equation (4) }
$$

$S^{\prime}$ is the set of smoothed performance data of a construction task with BIM support where 


$$
S_{n}^{\prime}=\alpha D_{n}^{\prime}+(1-\alpha) S_{n-1}^{\prime}
$$

\section{Step 4: Identify the "best-fit" learning curves}

This step involves the identification of a learning curve model which could best describe the performance data as shown in Equations (3) and (4). Numerous models exist for measuring the learning effects. Unlike previous studies to pre-set a learning curve model (e.g. Boeing, Stanford “B”), this research will explore all the learning curves to find the ones that "best-fit" the two sets of performance data respectively. Programs can be designed in Matlab ${ }^{\circledR}$ to conduct curve fitting to select the "best-fit" ones from the learning curves listed in Table 1. The authors have tried these in $M a t l a b{ }^{\circledR}$ in our own personal computers (PCs) and each process cost less than one second; encouragingly, modern fast computers and software make a full trial of all the learning curves possible.

A method called the 'least-square curve fitting analysis' (LSCFA) was used to evaluate the fitness of a learning curve model that describes the trend of data (Everett and Farghal, 1994; Wong et al., 2007). Means-squared error (MSE) as shown below is usually the specific indicator for the LSCFA:

$M S E=\frac{\sum_{j=1}^{N}\left(x_{j}-y_{j}\right)^{2}}{N}$ Where $N$ is the number of the performance data, $x_{j}$ is the performance data at the $j$ th cycle after processing, $y_{j}$ is the performance data agreeing with the learning curve model at the jth cycle (Wong et al., 2007). Test of fitness is conducted by comparing the MSE; The lower the MSE, the better the fitness of the learning model in describing the performance data. By following this LSCFA, a "best-fit" learning curve for each dataset can be identified in this step, and their corresponding MSE can be shown in Equations (5) and (6):

$$
F=f(m) \text { when } M S E=\frac{\sum_{j=1}^{m}\left(S_{j}-f(j)\right)^{2}}{m} \text { is minimal Equation (5) }
$$

$F$ is the "best-fit" learning curve for a repetitive task without BIM support 
$F^{\prime}=f^{\prime}(n)$ when $M S E^{\prime}=\frac{\sum_{j=1}^{n}\left(S_{j}^{\prime}-f^{\prime}(j)\right)^{2}}{n}$ is minimal Equation (6)

$F^{\prime}$ is the "best-fit" learning curve for a repetitive task with BIM support

The two learning curves identified through the analytical processes can also be illustrated in graphics (Fig. 3). The learning curves were derived based on smoothed performance data. It should be noted that the learning curves as shown in Fig. 3 could be in an arc (e.g. an exponential model) although they are in straight lines for demonstration purpose here.

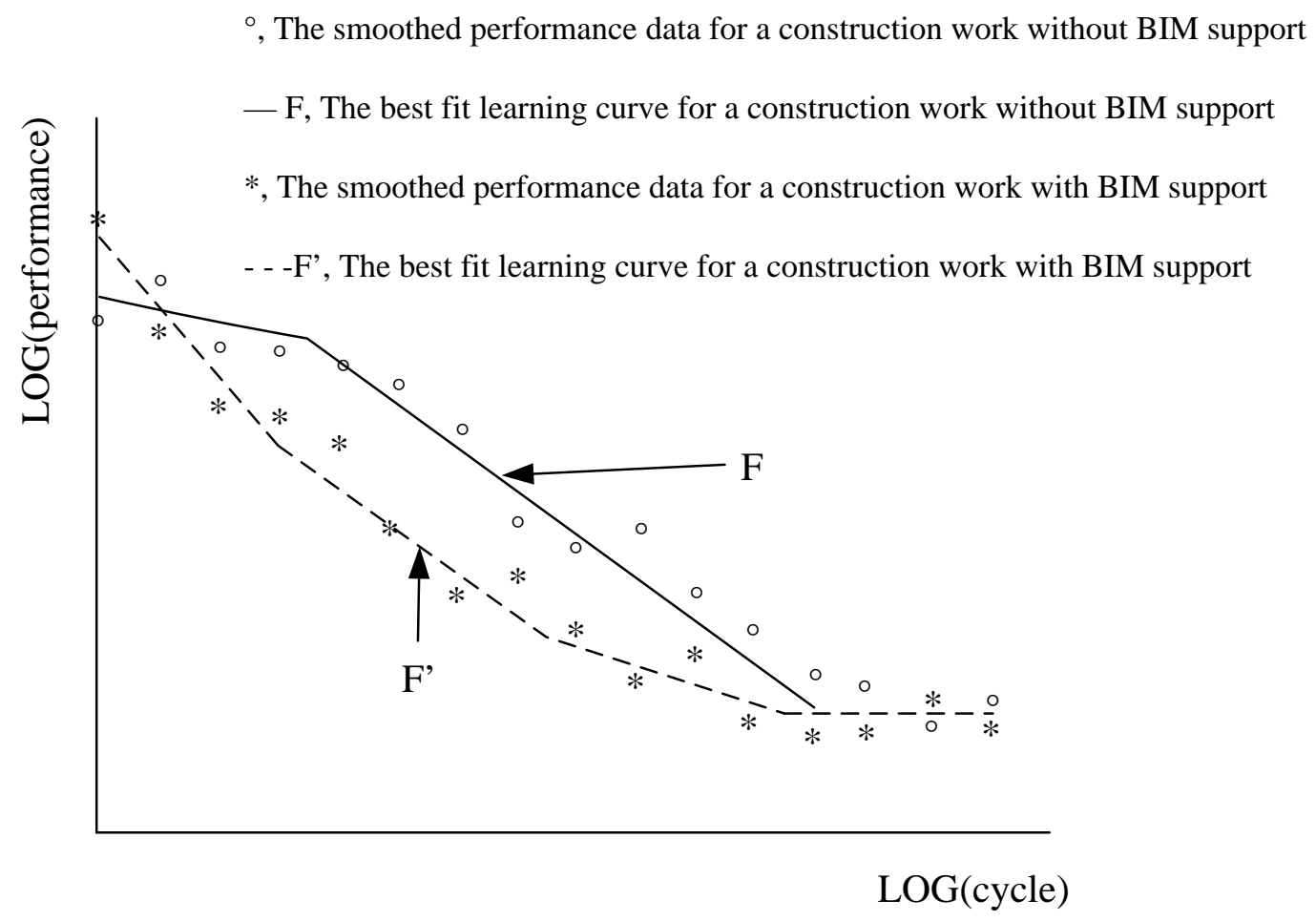

Fig. 3 An illustration of learning curves "best-fit” for construction works with and without BIM supported

From now on, further analysis will be based on the two learning curve models in Equations (5) and (6) rather than the datasets as shown in Equations (3) and (4). Learning is a continuous process as reflected by the continuous learning curves while the discrete data collected is for the purpose of identifying the continuous curves. Furthermore, the learning curves identified through the analytical processes help reduce the noise in the discrete performance data, and thus, are better in terms of 
reflecting the learning effects.

\section{Step 5: Compare the two learning curves}

Two learning curves were identified as a result of previous analytical processes. The subtraction of the two learning curve models is the learning effects contributed by BIM. This can be shown in Equation (7).

$L_{\text {effBIM }}(T)=F-F^{\prime}=f(T)-f^{\prime}(T) \quad$ Equation (7)

where $L_{\text {efBIIM }}(T)$ denotes the learning effects contributed by BIM in a given cycle $T$.

\section{Step 6: Calculate learning effects contributed by BIM}

The aggregate learning effects contributed by BIM in the whole construction work can be shown in the integration Equation (8).

$$
L_{\text {effBIM }}=\int L_{\text {effBIM }}(T)=\int\left(f(T)-f^{\prime}(T)\right) \quad \text { Equation (8) }
$$

where $L_{\text {effBIM }}$ denotes the aggregate learning effects contributed by BIM. In graphic, it was represented by the shadow area in Fig. 4.

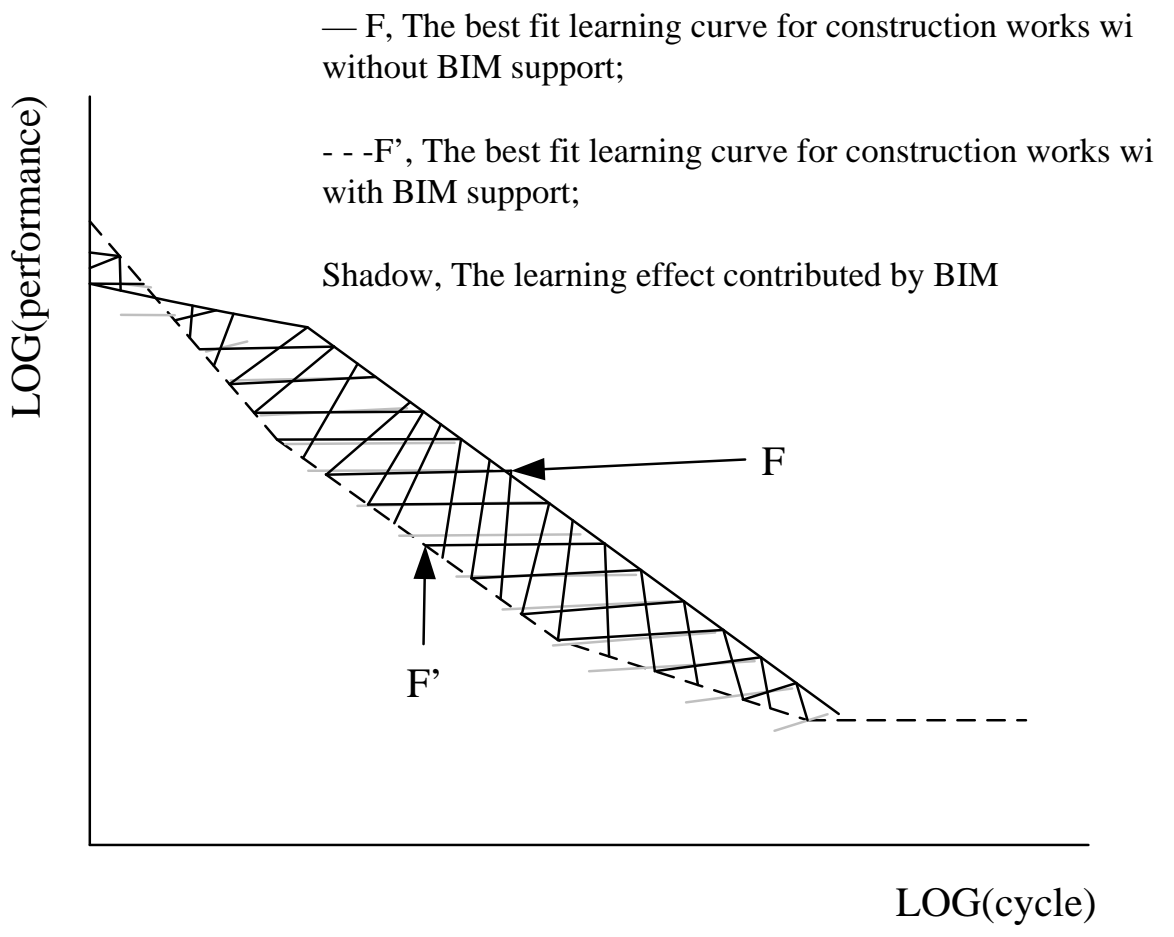

Fig. 4 An illustration of learning effects contributed by BIM 


\section{A case study for illustrating the application of $L_{\text {effBIM }}$}

The above analytic processes lead to a model $L_{\text {effBIM }}$ that enables BIM users to calculate the learning effects contributed by BIM in construction tasks. For simplicity of discussion but without losing generality, a case is employed to demonstrate how this model can be applied in real-life construction tasks. The case is a synthesis of several real-life projects where BIM has been implemented. The reasons to do so are threefold. Firstly, owing to the difficulties to derive all the datasets for this case study, some missing data is hypothesized therefore this case should not be claimed as a single real-life project. Nonetheless, the data collection and processing are described here so that potential users of the $L_{\text {effBIM }}$ model can understand how to distil their own datasets when data accessibility is better. Secondly, it is necessary to ensure that the data used here will not lead to the identification of the projects according to the term of the data policy agreement. Thirdly, the main purpose of this case study is to demonstrate how the generic model and the analytic processes are applied; identifying specific learning effects in a certain project is beyond the ambition of this paper.

The project is a 66-floors high-rise building in a very compact metropolitan area. The gross floor area (GFA) of the standard floor is $3,200 \mathrm{~m}^{2}$. It adopts a typical structure for high-rise buildings which is called central core plus mega columns and outrigger system. The main tasks for erecting the building include the construction of the central core, mega columns, slabs, and the installation of the outriggers. It adopts the traditional cast in-situ concrete building technology with all the materials including steels, mixed concrete, formworks and falseworks, being transported from outside the site. From the $5^{\text {th }}$ to $45^{\text {th }}$ floors is typical floor construction. Here we focus on the construction of floor slabs. During the construction, a floor is often divided into four bays with each bay containing repetitive construction activities as listed in the first row of Table 2. The table gives the quantity information about these construction activities in the region.

Table 2 The characteristics activities of one typical bay

\begin{tabular}{lllllllll}
\hline Activities & Raising & Setting & Erection & Fixing & Hoisting & Lifting & Concrete & Raising \\
& safety & up & of & precast & rebar & up & (slab/beam/column) & Holland \\
& screen & Table & Column & edge & (HR) & placing & (CSBC) & hoist \\
& $(\mathrm{RS})$ & Form & Formwork & beam & & boom & & $(\mathrm{RH})$ \\
& $(\mathrm{SF})$ & $(\mathrm{EF})$ & $(\mathrm{FE})$ & & $(\mathrm{LB})$ & & \\
\hline
\end{tabular}




\begin{tabular}{lllllllll}
\hline Quantity & 39 & 81 & 4 & 27 & 30.7 & 2 & 418 & 2 \\
Unit & Nos. & Nos. & Nos. & Nos. & Tons & Nos. & $\mathrm{m}^{3}$ & Nos. \\
\hline
\end{tabular}

Normally, a floor will take $\mathrm{N}$ days to complete depending on the floor areas, site conditions, construction plan, and configuration of available resources (e.g. project teams, equipment, and logistic and supply chain). By repeating the construction activities, a building escalates like a spiral. The contractor has successfully constructed other high-rise buildings previously and therefore the experience has been helpful in winning this contract. But this new project is unique in two main aspects: the site conditions are different and the time scale for this project is tight. The contractor decided to adopt BIM, or more specifically the Dassault Systemes (DS), to rehearse and optimize the construction plan for a typical floor. It is expected that through these rehearsal, optimization, and learning, the project team can construct a floor quicker while meeting the quality standard and cost requirement. Similar previous projects in terms of floor areas, completion duration, and investment in this company were selected for comparison.

\section{Step 1: Identify repetitive construction tasks to study}

In this case study, the sequential set of works RS, SF, EF, FE, HR, LB, CSBC and RH for a bay on each standard floor is treated as a single and repetitive construction activity, or using previous term, a cycle. As a meaningful representative of construction tasks in high-rise buildings, this integral activity has been investigated by several other studies (e.g. Tam et al., 2002; Li et al., 2008).

\section{Step 2: Collect performance data}

Performance data in man-hours/cycle were collected for two situations: previous works by the contractor, and current works with BIM support in this new project. Apparently, the floor areas of the bays make big difference; the larger the bay area, the more man-hours need for constructing such a bay/cycle. Therefore, man-hours $/ \mathrm{m}^{2}$ associated with each bay is adopted as the unit for performance data. Readers may refer back to the aforementioned Step 2 suggesting that ratio data such as productivity in man-hour $/ \mathrm{m}^{2}$ can be adopted to reduce the impact of factors such as floor areas, number of workers, etc. In so doing, it can be considered that the two sets of works are identical with only one different factor of BIM. 
From the project report, it is found that the performance of previous project without BIM is around 6.32 man-hours $/ \mathrm{m}^{2}$ and gradually reached 4.81 man-hours $/ \mathrm{m}^{2}$. In contrast, performance of the current project with BIM is about 6.27 man-hours $/ \mathrm{m}^{2}$ and gradually reached 4.83 man-hours $/ \mathrm{m}^{2}$. It should be articulated herein again that the beginning set of data is calculated from real cases while the later sets are hypothesized based on the research with the contractor. The reason is that in real construction practice, a project manager never slavishly follows the plan as shown in above Table 2 - when there are spare working areas and resources, a project manager often makes a quick decision commanding the project team to move ahead. Nonetheless, this real dataset can be distilled from onsite records, i.e. site logs, time sheets filled by employees, progress reports, inventory records, although it is difficult for us to obtain all these past records. The data set can be shown from rows 1 to 6 in Table 3. Readers may be drawn attention to the productivity KPI of the St George Wharf development in South London, UK. In the St George Wharf development project, productivity was ranged from around 3.8 to 5.1 man-hours $/ \mathrm{m}^{2}$.

Table 3 Performance data for constructing a standard bay in two different situations

\begin{tabular}{|c|c|c|c|c|c|c|c|c|c|c|c|c|c|c|c|c|c|c|}
\hline 1 & \multirow{3}{*}{ 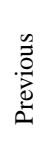 } & \multirow{3}{*}{\multicolumn{2}{|c|}{ 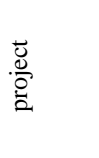 }} & & Floor & \multicolumn{4}{|c|}{5} & \multicolumn{4}{|c|}{6} & \multicolumn{4}{|c|}{7} & \\
\hline 2 & & & & & Bay or cycle & 1 & 2 & 3 & 4 & 5 & 6 & 7 & 8 & 9 & 10 & 11 & 12 & 13 \\
\hline 3 & & & & & Man-hours $/ \mathrm{m}^{2}$ & 6.32 & 6.12 & 6.24 & 6.33 & 6.38 & 6.37 & 6.34 & 6.27 & 6.18 & 6.08 & 5.97 & 5.85 & 5.72 \\
\hline 4 & \multirow{3}{*}{$\begin{array}{l}\text { 节 } \\
\text { J }\end{array}$} & \multirow{3}{*}{\multicolumn{2}{|c|}{ 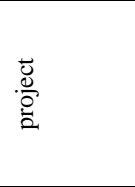 }} & & Floor & \multicolumn{4}{|c|}{5} & \multicolumn{4}{|c|}{6} & \multicolumn{4}{|c|}{7} & \\
\hline 5 & & & & & Bay or cycle & 1 & 2 & 3 & 4 & 5 & 6 & 7 & 8 & 9 & 10 & 11 & 12 & 13 \\
\hline 6 & & & & & Man-hours $/ \mathrm{m}^{2}$ & 6.27 & 6.25 & 6.2 & 5.93 & 5.81 & 5.73 & 5.65 & 5.55 & 5.47 & 5.4 & 5.34 & 5.29 & 5.24 \\
\hline 7 & \multirow{3}{*}{ 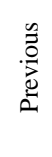 } & \multirow{3}{*}{$\frac{2}{2}$} & \multirow{3}{*}{ 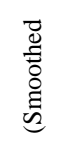 } & & Floor & \multicolumn{4}{|c|}{5} & \multicolumn{4}{|c|}{6} & \multicolumn{4}{|c|}{7} & \\
\hline 8 & & & & & Bay or cycle & 1 & 2 & 3 & 4 & 5 & 6 & 7 & 8 & 9 & 10 & 11 & 12 & 13 \\
\hline 9 & & & & & Man-hours $/ \mathrm{m}^{2}$ & 6.32 & 6.22 & 6.23 & 6.28 & 6.33 & 6.35 & 6.35 & 6.31 & 6.24 & 6.16 & 6.07 & 5.96 & 5.84 \\
\hline 10 & \multirow{3}{*}{$\begin{array}{l}\text { 节 } \\
\text { Uु }\end{array}$} & \multirow{3}{*}{ 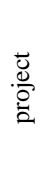 } & \multirow{3}{*}{ 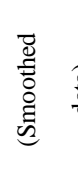 } & & Floor & \multicolumn{4}{|c|}{5} & \multicolumn{4}{|c|}{6} & \multicolumn{4}{|c|}{7} & \\
\hline 11 & & & & & Bay or cycle & 1 & 2 & 3 & 4 & 5 & 6 & 7 & 8 & 9 & 10 & 11 & 12 & 13 \\
\hline 12 & & & & & Man-hours $/ \mathrm{m}^{2}$ & 6.27 & 6.26 & 6.23 & 6.08 & 5.95 & 5.84 & 5.74 & 5.65 & 5.56 & 5.48 & 5.41 & 5.35 & 5.29 \\
\hline
\end{tabular}

\section{Step 3: Data processing}

By using the Equation (3) and (4) in Matlab®, the smoothed performance data can be derived as shown in rows 7 and 12 in Table $3(\alpha=0.5)$. Everett and Farghal (1997) discussed the effects of different smoothing parameters and found that $\alpha=0.5$ is better than $\alpha=0.3$ in fitting the performance data therefore this research adopts $\alpha=0.5$. 


\section{Step 4: Identify “best-fit” learning curves}

By programming the fitting process in the Matlab ${ }^{\circledR}$ again, the two learning curves that best fit the smoothed performance data are identified as shown in Equations (9) and (10), and in Fig. 5.

$F(T)=10^{\left(0.8004-0.1268 \lg (T)+0.3715(\lg (T))^{2}-0.2576(\lg (T))^{3}\right)}$ or

$\lg F(T)=0.8004-0.1268 \lg (T)+0.3715(\lg (T))^{2}-0.2576(\lg (T))^{3}$ when $M S E=0.0011$

Equation (9)

$F^{\prime}(T)=10^{\left(0.7991-0.0147 \lg (T)-0.0727(\lg (T))^{2}\right)}$ or

$\lg F^{\prime}(T)=0.7991-0.0147 \lg (T)-0.0727(\lg (T))^{2}$ when $M S E^{\prime}=0.0008 \quad$ Equation $(10)$

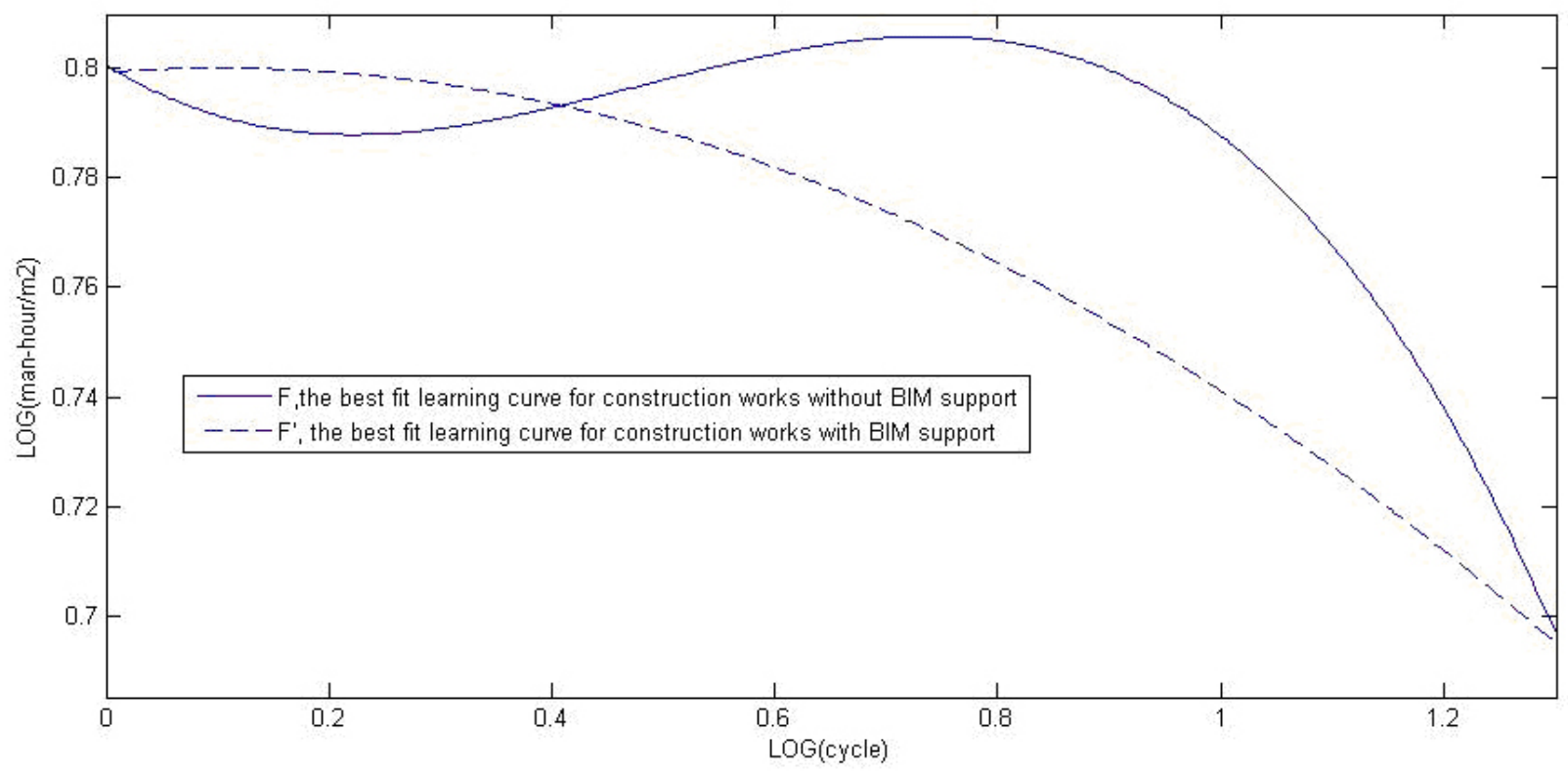

Fig. 5 The comparison of the two learning curves for the hypothetical case study

Step 5: Compare the two learning curves and Step 6: Calculate learning effects contributed by BIM

The aggregated learning effects in the twenty cycles can be calculated as Equation (11):

$L_{\text {effBIM }}=\int_{1}^{20} 10^{\left(0.8004-0.1268 \lg (T)+0.3715(\lg (T))^{2}-0.2576(\lg (T))^{3}\right)}-10^{\left(0.7991-0.0147 \lg (T)-0.0727(\lg (T))^{2}\right)}=6.99$ man-hour $/ \mathrm{m}^{2}$ 
Equation (11)

Aggregated learning effects indicate the cumulative productivity improvement in the concerned cycles. Saved money can be derived based on the man-hour rate and the floor area. Assume that the floor area of a cycle (one quarter of the entire floor) is $800 \mathrm{~m}^{2}$ and the man-hour rate is $10 \$ /$ hour, the aggregate learning effects within the 20 cycles (5 floors) is \$ 55,920 in monetary term. This tangible benefit is useful to justify the investment of time and budget on BIM, particularly by comparing it with the cost of BIM.

\section{Conclusions and future development}

Identifying and measuring the benefits of BIM as a learning tool has both academic and practical value. It can improve people's understanding of BIM as well as help justify the investment in it. This paper envisages that BIM provides a less expensive virtual environment for "learning by doing” not only for physically repetitive construction tasks but also for project management activities. Moreover, this paper empirically models the learning effects empowered by BIM through utilizing the classic learning curve theory. By following a series of six analytical processes, a model $L_{\text {effBIM }}$ is developed to recognize the learning effects in construction tasks. The applicability and understanding of this model are further enhanced by using mathematical language and graphic tools. Rather than focusing on identification of the learning effects in a given project, it is better to treat $L_{\text {effBIM }}$ as a generic model that allows different BIM users to assess the learning effects in monetary term by inputting their own project data.

A model makes sense only when users are willing to use it. Future research will be conducted to encapsulate the generic model in a software package and invite BIM users to test the model using their own project data. In considering the users that are geographically dispersed, we tend to make the software an online solution by engaging Net technologies. Particular considerations will be given to the guidance for collecting data from various construction tasks. It is believed that raw data is in existence in one way or another but needs to be distilled and tailor-made before it can be fed into the

$L_{\text {effBIM }}$. Further research will also be conducted to help interpret the test results with the hope to achieve more benefits through the wider implementation of BIM as a valuable tool in construction 
tasks.

\section{Acknowledgement}

This research was sponsored by the Seed Funding Programme for Basic Research (Project No. 201010159019) at the University of Hong Kong, HKSAR. The authors also would like to thank the construction company which helped data collection although its name will not be shown here.

\section{References}

Adler, P. S. and Clark, K. B. (1991). "Behind the learning curve: A sketch of the learning process.” Management Science, 37(3), 267-281.

Argote, L., Beckman, S. L. and Epple, E. (1990). "The persistence and transfer of learning in industrial settings.” Management Science, 36(2), 140-154.

Azhar, S., Hein, M. and Sketo, B. (2008). Building information modeling(BIM): Benefits, risks and challenges. https://fp.auburn.edu/heinmic/Pubs/ASC\%202008-BIM\%20Benefits.pdf, (accessed on 21th July, 2009).

Badiru, A. B. (1992). “Computational survey of univariate and multivariate learning curve models.” IEEE Transactions on Engineering Management, 39(2), 176-188.

Bazjanac, V. (2008). "Impact of the U.S. national building information model standard (NBIMS) on building energy performance simulation.” http://escholarship.org/uc/item/3v95d7xp. (accessed on 8th Jan 2010).

Becerik-Gerber, B. and Kensek, K. (2010). “Building information modeling in architecture, engineering, and construction: emerging research directions and trends.” Journal of Professional Issues in Engineering Education and Practice, 136(3), 139-147.

Center for Integrated Facility Engineering (CIFE). (2007). CIFE Technical Reports. http://cife.stanford.edu/Publications/index.html. (accessed on 8th Jan 2010).

Couto, J. P. and Teixeira, J. C. (2005). "Using linear model for learning curve effect on highrise floor construction.” Construction Management and Economics, 23(4), 355-364.

Dennis, M. G. (2006). “Does learning building information modeling improve the plan reading skills of construction management students?” http://ascpro0.ascweb.org/archives/cd/2007/paper/CEUE146002007.pdf (accessed on 11th Jan 
2010).

Dennis, M. G. (2007). "What impact does using building information modeling have on teaching estimating to construction management students?” http://ascpro0.ascweb.org/archives/cd/2008/paper/CEUE179002008.pdf (accessed on 11th Jan 2010).

Dikmen, I., Birgonul, M. T. and Ataoglu, T. (2005). "Empirical investigation of organisational learning ability as a performance driver in construction.” Knowledge management in the construction industry: A socio-technical perspective, Samad, A. (eds.), Idea Group Publishing, Hershey, 130-149.

Eastman, C. M., Teicholz, P., Sacks, R., and Liston, K. (2008). BIM Handbook: A Guide to Building Information Modeling for Owners, Managers, Architects, Engineers, Contractors, and Fabricators, Wiley, Hoboken, N.J.

Epple, D., Argote, L. and Devadas, R. (1991). “Organizational learning curves: A method for investigating intra-plant transfer of knowledge acquired through learning by doing." Organization Science, 2(1), 58-70.

Everett, J. G. and Farghal, S. (1994). "Learning curve predictors for construction field operations.” Journal of Construction and Management, 120(3), 603-616.

Everett, J. G. and Farghal, S. H. (1997). “Data representation for predicting performance with learning curves.” Journal of Construction Engineering and Management, 123(1), 46-52.

Farghal, S. H and Everett, J. G. (1997). “Learning curves: Accuracy in predicting future performance.” Journal of Construction Engineering and Management, 123(1), 41-45.

Fox, S. and Hietanen, J. (2007). "Interorganizational use of building information models: potential for automational, informational and transformational effects.” Construction Management and Economics, 25(3), 289-296.

Goedert, J. D. and Meadati, P. (2008). "Integrating construction process documentation into building information modeling.” Journal of Construction Engineering and Management, 134(7), 509-516.

Hedges, K. E. and Denzer, A. S. (2008). "How a collaborative architecture influences structural engineering education.” ASCE Proceedings of the 2008 Structures Congress, in Vancouver, British Columbia, Canada, April 24-26 2008.

Ibrahim, R. and Rahimian, F. P. (2010). "Comparison of CAD and manual sketching tools for teaching 
architectural design.” Automation in Construction, 19(8), 978-987.

Kaner, I., Sacks, R., Kassian, W. and Quitt, T. (2008). "Case studies of BIM adoption for precast concrete design by mid-sized structural engineering firms.” Journal of Information Technology in Construction, 13, 303-323.

Lieberman, M. B. (1987). "The learning curve, diffusion, and competitive strategy." Strategic Management Journal, 8(5), 441-452.

Li, H., Guo, H. L., Skibniewski, M. and Skitmore, M. (2008a). "Using the IKEA model and virtual prototyping technology to improve construction process.” Construction Management \& Economics, 26(9), 991-1000.

Li, H., Huang, T., Kong, C. W. Guo, H. L., Baldwin, A., Chan, N. And Wong, J. (2008b). “Integrating design and construction through virtual prototyping." Automation in Construction, 17(8), 915-922.

Li, H., Lu, W. S. and Huang, T. (2009). "Rethinking project management and exploring virtual design and construction as a potential solution”. Construction Management and Economics, 27(4), 363 $-371$.

Ling, F. Y. Y. and Liu, M. (2004). "Using neural network to predict performance of design-build projects in Singapore.” Building and Environment, 39, 1263-1274.

Lu, W. S. and Li, H. (2011). "Building Information Modeling and changing construction practices.” Automation in Construction, 20(2), 99-100.

Lutz, J. D., Halpin, D. W. and Wilson, J. R. (1994). "Simulation of learning development in repetitive construction.” Journal of Construction Engineering and Management, 120(4), 753-773.

Nembhard, D. A. and Uzumeri, M. V. (2000). “An individual-based description of learning within an organization.” IEEE Transactions on Engineering Management, 47(3), 370-378.

Oglesby, C. H., Parker, H. W. and Howell, G. A. (1989). Productivity improvement in construction. McGraw-Hill, New York.

Patrick, C. S. and Raja, R. A. (2007). Evaluating the impact of building information modeling (BIM) on construction. $7^{\text {th }}$ International Conference on Construction Application of Virtual Reality, 206-215.

Peterson, F., Hartmann, T., Fruchter, R. and Fischer, M. (2011). "Teaching construction project management with BIM support: experience and lessons learned.” Automation in Construction, 
20(2), 115-125.

Sacks, R. and Barak, R. (2008). "Impact of three-dimensional parametric modeling of buildings on productivity in structural engineering practice.” Automation in Construction, 17(4), 439-449.

Sacks, R. and Barak, R. (2010). "Teaching building information modeling as an integral part of freshman year civil engineering education.” Journal of Professional Issues in Engineering Education and Practice, 136(1), 30-38.

Sacks, R., Eastman, C. M., Lee, G., and Orndorff, D. (2005). “A target benchmark of the impact of three-dimensional parametric modeling in precast construction.” PCI Journal, 50(4), 126-139.

Sacks, R., Koskela, L., Dave, B. A. and Owen, R. (2010a). "Interaction of lean and building information modeling in construction.” Journal of Construction Engineering and Management, 136(9), 968-980.

Sacks, R., Radosavljevic, M. and Barak, R. (2010b). "Requirements for building information modeling based lean production management systems for construction.” Automation in Construction, 19(5), 641-655.

Sacks, R., Treckmann, M. and Rozenfeld, O. (2009). "Visualization of work flow to support lean construction.” Journal of Construction Engineering and Management, 135(12), 1307-1315.

Schlueter, A. and Thesseling, F. (2009). "Building information model based energy/exergy performance assessment in early design stages.” Automation in Construction, 18(2), 153-163.

Succar, B. (2009). "Building information modeling framework: a research and delivery foundation for industry stakeholders.” Automation in Construction, 18(3), 357-375.

Tam, C. M., Deng, Z. M. and Zeng, S. X. (2002). “Evaluation of construction methods and performance for high rise public housing construction in Hong Kong.” Building and Environment, 37, 983 - 991.

Thomas, H. R., Mathews, C. T. and Ward, J. G. (1986). "Learning curve models of construction productivity.” Journal of Engineering and Management, 112(2), 245-258.

Uzumeri, M. and Nemhard, D. (1998). “A population of learners: a new way to measure organizational learning.” Journal of Operations Management, 16(5), 515-528.

Wong, P. S. P., Cheung, S. O. and Hardcastle, C. (2007). “Embodying learning effect in performance prediction”. Journal of Construction Engineering and Management, 133(6), 474-482.

Yelle, L. E. (1979). “The learning curve: historical review and comprehensive survey.” Decision 
Sciences, 10(2), 302-328. 
